\title{
Impact of "Time-From-Biopsy-to-
} Prostatectomy" on Adverse Oncological Results in Patients With Intermediate and High-Risk Prostate Cancer

\section{OPEN ACCESS}

Edited by:

Marianne Schmid,

University Medical Center

Göttingen, Germany

Reviewed by:

Marco Roscigno,

Ospedale Papa Giovanni XXIII, Italy Katharina Boehm,

Johannes Gutenberg University

Mainz, Germany

Hans Christoph Von Knobloch,

University of Göttingen, Germany

*Correspondence:

Andreas Becker

andreas.becker@kgu.de

Specialty section:

This article was submitted to

Genitourinary Surgery,

a section of the journal

Frontiers in Surgery

Received: 13 May 2020

Accepted: 21 August 2020

Published: 25 September 2020

Citation:

Engl T, Mandel P, Hoeh B, Preisser F Wenzel $M$, Humke $C$, Welte $M$, Köllermann J, Wild P, Deuker M, Kluth LA, Roos FC, Chun FKH and Becker A (2020) Impact of "TimeFrom-Biopsy-to-Prostatectomy" on Adverse Oncological Results in Patients With Intermediate and High-Risk Prostate Cancer.

Front. Surg. 7:561853.

doi: 10.3389/fsurg.2020.561853

\begin{abstract}
Tobias Engl ${ }^{1,2}$, Philipp Mandel ${ }^{1}$, Benedikt Hoeh ${ }^{1,2}$, Felix Preisser ${ }^{1}$, Mike Wenzel ${ }^{1}$, Clara Humke ${ }^{1}$, Maria Welte ${ }^{1}$, Jens Köllermann ${ }^{3}$, Peter Wild ${ }^{3}$, Marina Deuker ${ }^{1}$, Luis A. Kluth ${ }^{1}$, Frederik C. Roos ${ }^{1}$, Felix K. H. Chun ${ }^{1}$ and Andreas Becker ${ }^{1 *}$
\end{abstract}

${ }^{1}$ Department of Urology, University Hospital Frankfurt, Frankfurt am Main, Germany, ${ }^{2}$ Urogate Associates, Frankfurt am Main, Germany, ${ }^{3}$ Department of Pathology, University Hospital Frankfurt, Frankfurt am Main, Germany

Objective: Many patients with localized prostate cancer ( $\mathrm{PCa}$ ) do not immediately undergo radical prostatectomy (RP) after biopsy confirmation. The aim of this study was to investigate the influence of "time-from-biopsy-to- prostatectomy" on adverse pathological outcomes.

Materials and Methods: Between January 2014 and December 2019, 437 patients with intermediate- and high risk PCa who underwent RP were retrospectively identified within our prospective institutional database. For the aim of our study, we focused on patients with intermediate- $(n=285)$ and high-risk $(n=151)$ PCa using D'Amico risk stratification. Endpoints were adverse pathological outcomes and proportion of nerve-sparing procedures after RP stratified by "time-from-biopsy-to-prostatectomy": $\leq 3$ months vs. $>3$ and $<6$ months. Medians and interquartile ranges (IQR) were reported for continuously coded variables. The chi-square test examined the statistical significance of the differences in proportions while the Kruskal-Wallis test was used to examine differences in medians. Multivariable (ordered) logistic regressions, analyzing the impact of time between diagnosis and prostatectomy, were separately run for all relevant outcome variables (ISUP specimen, margin status, pathological stage, pathological nodal status, LVI, perineural invasion, nerve-sparing).

Results: We observed no difference between patients undergoing RP $\leq 3$ months vs. $>3$ and $<6$ months after diagnosis for the following oncological endpoints: PT-stage, ISUP grading, probability of a positive surgical margin, probability of lymph node invasion (LNI), lymphovascular invasion (LVI), and perineural invasion (pn) in patients with intermediate- and high-risk PCa. Likewise, the rates of nerve sparing procedures were 84.3 vs. $87.4 \%(\rho=0.778)$ and $61.0 \%$ vs. $78.8 \%$ $(p=0.211)$, for intermediate- and high-risk PCa patients undergoing surgery after $\leq 3$ months vs. $>3$ and $<6$ months, respectively. In multivariable adjusted analyses, a time to surgery $>3$ months did not significantly worsen any of the outcome variables in patients with intermediate- or high-risk PCa (all $p>0.05$ ). 
Conclusion: A "time-from-biopsy-to-prostatectomy" of $>3$ and $<6$ months is neither associated with adverse pathological outcomes nor poorer chances of nerve sparing RP in intermediate- and high-risk PCa patients.

Keywords: prognosis, waiting time, delayed treatment, deferred treatment, histological outcomes, radical prostatectomy, prostate cancer

\section{INTRODUCTION}

There are numerous therapeutic options available for treatment of localized prostate cancer (PCa). Patients and their treating physicians can choose between active surveillance if the criteria are met, open or minimally invasive radical prostatectomy (RP), external radiotherapy, brachytherapy or, under certain circumstances, focal therapy (1). This decision can be very difficult for some patients. Many, especially critical and informed patients need time to make their decision and often ask for a second or third opinion. For this reason, some patients may have a significant delay in treatment, while other patients may be operated on promptly. Further potential reasons for delayed treatment include patient's anxiety, desire to obtain more detailed information regarding therapeutic options, necessity for treatment of comorbidities or limited surgical capacities and long waiting lists. Most studies show no influence of the time from diagnosis to surgery of low or intermediate risk prostate cancer on the oncological outcome (1-16). However, a recent Canadian multicentre study observed a higher risk of biochemical recurrence (BCR) in high-risk PCa patients undergoing $\mathrm{RP}$ after more than 3 months of waiting time (17). In the context of inverse stage migration with a trend toward surgical treatment of high-risk PCa and the need for prioritization strategies during the current COVID-19 pandemic, these concerns seem even more relevant (18).

To address this void, we investigated the impact of the timefrom-biopsy-to-prostatectomy on histopathological outcomes and chance for nerve sparing surgery in men who underwent RP for intermediate- and high-risk PCa according to the D'Amico classification (19).

\section{MATERIALS AND METHODS}

\section{Study Population}

Patients who underwent RP between January 2014 and December 2019 were retrospectively identified form our prospective institutional database (University Hospital Frankfurt, University of Frankfurt, Frankfurt am Main, Germany). All patients had given written consent and the study was approved by the

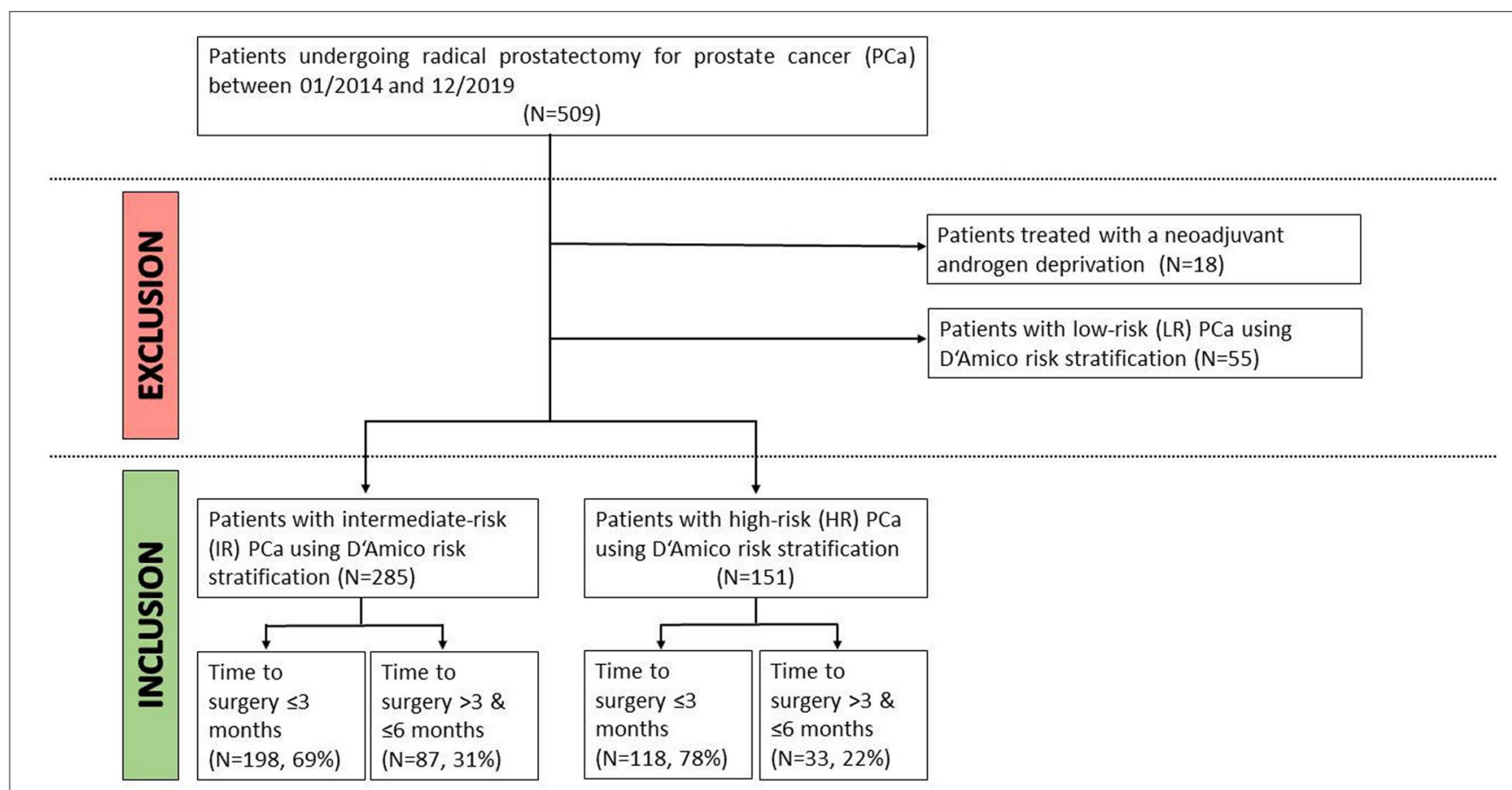

FIGURE 1 | Inclusion- and exclusion criteria for our study of patients undergoing immediate ( $\leq 3$ months) vs. delayed (>3 and $<6$ months) radical prostatectomy for intermediate- or high-risk prostate cancer. 
local institutional review boards of the University Cancer Centre Frankfurt and the Ethical Committee at the University Hospital Frankfurt.

Patients treated with a neoadjuvant androgen deprivation ( $n=18,3.5 \%$ ) were excluded from our study, leaving 437 patients with intermediate- an high-risk PCa meeting the abovementioned criteria (Figure 1). For the aim of our study, we focused on patients with intermediate- $(n=285)$ and high-risk $(n=151)$ prostate cancer using D'Amico risk stratification (19). Specifically, intermediate- vs. high risk PCa were defined as: PSA $10-20 \mathrm{ng} / \mathrm{ml}$, Gleason sum $>6$, clinical stage $\geq$ T2a, vs. PSA $\geq 20 \mathrm{ng} / \mathrm{ml}$, Gleason sum 8-10, clinical stage $>\mathrm{T} 2 \mathrm{c}$ ).

Preoperative staging examinations were conducted according to the EAU guidelines: Lymph node imaging (using CT or MRI) and bone scans were conducted if PSA level $>10 \mathrm{ng} / \mathrm{mL}$ or Gleason score $>8$ or clinical stage $>\mathrm{T} 3$ was present.

\section{Surgical Approach and Study Design}

All patients underwent open retropubic or robotic-assisted laparoscopic RP. Each specimen was evaluated by two specialized uropathologists. Beginning in November 2017, radical prostatectomy was routinely performed with an intraoperative frozen section technique (NEUROSAFE) and with full functional length preservation of the prostatic urethra (FFLU) as described earlier $(20,21)$.

Patients were stratified by time from biopsy to surgery $\leq 3$ months vs. $>3$ and $<6$ months. Relevant outcome variables were pathologic Gleason grade, pT-stage, surgical margin status, lymph node involvement (LNI), lymphovascular invasion (LVI), perineural invasion (PNI), and nerve sparing procedure. Stratified subanalyses were performed for patients with intermediate- and high-risk prostate cancer according to the D’Amico classification (19).

\section{Statistical Analyses}

Descriptive statistics included frequencies and proportions for categorical variables. Medians and interquartile ranges (IQR) were reported for continuously coded variables. The chi-square test examined the statistical significance of the differences in proportions while the Kruskal-Wallis test was used to examine differences in medians. Moreover, multivariable (ordered) logistic regressions, analyzing the impact of time between diagnosis and prostatectomy, were separately run for all relevant outcome variables (ISUP specimen, margin status, pathological stage, pathological nodal status, LVI, perineural invasion, nervesparing). As control variables preoperative patient and tumor characteristics (age, BMI, prostate volume, PSA, cT stage, ISUP biopsy) were used. As statistical software STATA was used (version 14 for Windows, StataCorp LP, College Station, TX).

\section{RESULTS}

\section{Patient and Preoperative Tumor Characteristics}

Patient and preoperative tumor characteristics stratified by time from diagnosis (biopsy) to radical prostatectomy are summarized in Table 1. Overall, $72.5 \%(n=317)$ underwent surgery within
TABLE 1 | Preoperative characteristics of intermediate- and high-risk patients undergoing radical prostatectomy within 3 months after diagnosis compared to $>3$ and $\leq 6$ months after diagnosis.

\begin{tabular}{|c|c|c|c|c|}
\hline & $\begin{array}{l}\text { All patients } \\
(n=437)\end{array}$ & $\begin{array}{c}\text { Time to } \\
\text { surgery } \leq 3 \\
\text { months } \\
(n=317)\end{array}$ & $\begin{array}{c}\text { Time to surgery } \\
>3 \text { and } \leq 6 \\
\text { months } \\
(n=120)\end{array}$ & $p$-value \\
\hline $\begin{array}{l}\text { Age, median } \\
(\mathrm{IQR})\end{array}$ & $\begin{array}{c}67 \\
(71-61)\end{array}$ & $\begin{array}{c}66 \\
(71-61)\end{array}$ & $\begin{array}{c}67 \\
(72-61)\end{array}$ & 0.37 \\
\hline $\begin{array}{l}\mathrm{BMI}\left(\mathrm{kg} / \mathrm{m}^{2}\right) \\
\text { median }(\mathrm{QQR})\end{array}$ & $\begin{array}{c}26.2 \\
(28.7-24.0)\end{array}$ & $\begin{array}{c}26.2 \\
(28.7-24.0)\end{array}$ & $\begin{array}{c}25.4 \\
(28.6-24.2)\end{array}$ & 0.57 \\
\hline $\begin{array}{l}\text { Prostate } \\
\text { volume in ml, } \\
\text { median (IQR) }\end{array}$ & $38(50-30)$ & 38 (50-30) & 40 (58-30) & 0.47 \\
\hline cT-stage, \% & & & & 0.64 \\
\hline cT1 & 46.5 & 46.4 & 46.7 & \\
\hline cT2 & 49.9 & 50.5 & 48.3 & \\
\hline сT3 & 3.7 & 3.2 & 5.0 & \\
\hline $\begin{array}{l}\text { PSA (ng/ml), } \\
\text { median (IQR) }\end{array}$ & $\begin{array}{c}89.0 \\
(13.6-6.2)\end{array}$ & $\begin{array}{c}9.0 \\
(13.8-6.2)\end{array}$ & $\begin{array}{c}8.9 \\
(12.8-6.2)\end{array}$ & 0.54 \\
\hline $\begin{array}{l}\text { ISUP biopsy, } \\
\%\end{array}$ & & & & 0.03 \\
\hline 1 & 8.5 & 6.9 & 12.5 & \\
\hline 2 & 45.8 & 42.925 .2 & 53.3 & \\
\hline 3 & 22.9 & 15.1 & 16.7 & \\
\hline 4 & 14.4 & 9.8 & 12.5 & \\
\hline 5 & 8.5 & & 5.0 & \\
\hline D’Amico, \% & & & & 0.06 \\
\hline $\begin{array}{l}\text { Intermediate- } \\
\text { risk }\end{array}$ & 65.4 & 62.7 & 72.5 & \\
\hline High-risk & 34.6 & 37.4 & 27.6 & \\
\hline
\end{tabular}

3 months from diagnosis while 27.5\% $(n=120)$ underwent surgery between 3 and 6 months after diagnosis. There was no statistically significant difference according to age at surgery $(p=0.37)$, Body-Mass Index (BMI) $(p=0.57)$, prostate volume $(p=0.68)$, cT-Stage $(p=0.47)$, preoperative PSA $(p=0.54)$, and D'Amico classification $(p=0.06)$ between patients of the two subgroups. Only the biopsy ISUP Gleason grade grouping showed a significant difference between the two groups $(p=0.03)$.

\section{RP Histopathologic Characteristics}

Respectively, 65.4 and $34.0 .6 \%$ of the analyzed patients showed preoperative intermediate-risk and high-risk characteristics according to the D'Amico classification. We observed no difference between patients undergoing radical prostatectomy $\leq 3$ months vs. $>3$ and $<6$ months after diagnosis in terms of pT-stage, grading, probability of a positive surgical margin (PSM), probability of lymph node metastasis (LNI), lymphovascular invasion (LVI), or perineural invasion (PNI). This holds true for both patients with intermediate- and high-risk prostate cancer.

For intermediate-risk patients undergoing RP after $\leq 3$ vs. $>3$ and $<6$ months, the rates of a uni- or bilateral nerve sparing was 
TABLE 2a | Histopathological outcomes and rates of nerve sparing surgery for patients with intermediate risk prostate cancer according to D'Amico.

\begin{tabular}{|c|c|c|c|c|}
\hline & $\begin{array}{l}\text { All patients } \\
(n=285)\end{array}$ & $\begin{array}{c}\text { Time to } \\
\text { surgery } \leq 3 \\
\text { months } \\
(n=198)\end{array}$ & $\begin{array}{c}\text { Time to surgery } \\
>3 \text { and } \leq 6 \\
\text { months } \\
(n=87)\end{array}$ & $p$-value \\
\hline $\begin{array}{l}\text { ISUP } \\
\text { specimen (\%) }\end{array}$ & & & & 0.664 \\
\hline 1 & 9.0 & 8.6 & 9.7 & \\
\hline 2 & 58.5 & 60.1 & 55.3 & \\
\hline 3 & 23.9 & 23.7 & 24.3 & \\
\hline 4 & 3.7 & 2.5 & 5.8 & \\
\hline 5 & 5.0 & 5.1 & 4.9 & \\
\hline $\begin{array}{l}\text { Margins } \\
\text { status (\%) }\end{array}$ & & & & 0.242 \\
\hline RO & 79.7 & 77.8 & 83.5 & \\
\hline $\mathrm{R} 1$ & 20.3 & 22.2 & 16.5 & \\
\hline $\begin{array}{l}\text { Pathological } \\
\text { stage (\%) }\end{array}$ & & & & 0.996 \\
\hline$\leq \mathrm{pT} 2 \mathrm{c}$ & 66.8 & 66.7 & 67.0 & \\
\hline рT3a & 26.2 & 26.3 & 26.2 & \\
\hline$\geq \mathrm{pT} 3 \mathrm{~b}$ & 7.0 & 7.1 & 6.8 & \\
\hline $\begin{array}{l}\text { Pathological } \\
\text { nodal status } \\
(\%)\end{array}$ & & & & 0.650 \\
\hline pNO & 96.0 & 96.0 & 96.1 & \\
\hline pN1 & 4.0 & 4.0 & 3.9 & \\
\hline $\begin{array}{l}\text { Lymphovascular } \\
\text { invasion (\%) }\end{array}$ & 7.6 & 8.1 & 6.8 & 0.211 \\
\hline $\begin{array}{l}\text { Perineural } \\
\text { invasion (\%) }\end{array}$ & 68.1 & 67.2 & 69.9 & 0.593 \\
\hline $\begin{array}{l}\text { Nerve-sparing } \\
(\%)\end{array}$ & & & & 0.778 \\
\hline Unknown & 1.4 & 1.5 & 1.1 & \\
\hline None & 13.3 & 14.1 & 11.6 & \\
\hline Uni-/Bilateral & 85.3 & 84.3 & 87.4 & \\
\hline
\end{tabular}

84.3 vs. $87.4 \%$ ( $p=0.778$ ). For high-risk patients undergoing RP after $\leq 3$ vs. $>3$ and $<6$ months, the rates of a uni- or bilateral nerve sparing were 61.0 vs. $78.8 \%(p=0.211)$.

In multivariable adjusted analyses, a time to surgery $>3$ months did not significantly worsen any of the outcome variables in patients with intermediate- or high-risk PCa (all $p>0.05$ ) (Table 2).

\section{DISCUSSION}

Due to the current COVID-19 pandemic, prioritization, and delay of oncological surgeries represents a major contemporary issue, raising concerns regarding oncological safety of such delay not only in the academic community but also in many patients and their treating physicians (22).

In the context of intermediate- and high-risk prostate cancer, our present study analyzing 437 patients with D'Amico intermediate- and high-risk prostate cancer who underwent
TABLE $\mathbf{2 b}$ | Histopathological outcomes and rates of nerve sparing surgery for patients with high risk prostate cancer according to D'Amico.

\begin{tabular}{|c|c|c|c|c|}
\hline & $\begin{array}{l}\text { All patients } \\
(n=151)\end{array}$ & $\begin{array}{c}\text { Time to } \\
\text { surgery } \leq 3 \\
\text { months } \\
(n=118)\end{array}$ & $\begin{array}{l}\text { Time to surgery } \\
>3 \text { and } \leq 6 \\
\text { months } \\
(n=33)\end{array}$ & $p$-value \\
\hline $\begin{array}{l}\text { ISUP } \\
\text { specimen (\%) }\end{array}$ & & & & 0.233 \\
\hline 1 & 2.7 & 2.6 & 3.1 & \\
\hline 2 & 30.2 & 28.2 & 37.5 & \\
\hline 3 & 20.1 & 19.7 & 21.9 & \\
\hline 4 & 16.8 & 20.5 & 3.1 & \\
\hline 5 & 30.2 & 29.1 & 34.4 & \\
\hline $\begin{array}{l}\text { Margins } \\
\text { status (\%) }\end{array}$ & & & & 0.164 \\
\hline RO & 60.7 & 63.6 & 50.0 & \\
\hline $\mathrm{R} 1$ & 39.3 & 36.4 & 50.0 & \\
\hline $\begin{array}{l}\text { Pathological } \\
\text { stage (\%) }\end{array}$ & & & & 0.144 \\
\hline$\leq \mathrm{pT} 2 \mathrm{c}$ & 35.1 & 35.6 & 33.3 & \\
\hline рТЗа & 32.5 & 28.8 & 45.5 & \\
\hline$\geq \mathrm{pT} 3 \mathrm{~b}$ & 32.5 & 35.6 & 21.2 & \\
\hline $\begin{array}{l}\text { Pathological } \\
\text { nodal status } \\
(\%)\end{array}$ & & & & 0.066 \\
\hline pNO & 74.0 & 70.3 & 87.5 & \\
\hline $\mathrm{pN} 1$ & 26.0 & 29.7 & 12.5 & \\
\hline $\begin{array}{l}\text { Lymphovascular } \\
\text { invasion (\%) }\end{array}$ & 32.7 & 33.1 & 31.3 & 0.851 \\
\hline $\begin{array}{l}\text { Perineural } \\
\text { invasion (\%) }\end{array}$ & 80.7 & 78.0 & 90.6 & 0.245 \\
\hline $\begin{array}{l}\text { Nerve-sparing } \\
(\%)\end{array}$ & & & & 0.211 \\
\hline Unknown & 4.6 & 5.9 & 0 & \\
\hline None & 30.5 & 33.1 & 21.2 & \\
\hline Uni-/Bilateral & 64.9 & 61.0 & 78.8 & \\
\hline
\end{tabular}

prostatectomy after $<3$ months or 3 and $<6$ months after biopsy, implies two important messages.

First, a treatment delay of 3-6 months does not impair histopathologic outcomes. We observed no difference in terms of pT-stage, grading, probability of a positive surgical margin, probability of lymph node involvement (LNI), lymphovascular invasion (LVI), or perineural invasion (PNI).

Second, we observed that using a frozen section guided approach (NEUROSAFE) (20) the probability to undergo nervesparing surgery is also not affected by such treatment delay. Over $87 \%$ of patients with intermediate-risk and almost $80 \%$ of patients with high-risk PCa received uni- or bilateral-nerve sparing delayed RP.

Our results are in contrast with a recent study from Zanaty et al. who observed a higher risk of biochemical recurrence (BCR) in high-risk PCa patients undergoing RP after more than 3 months of waiting time (17). However, mean waiting time in this Canadian series of 619 patients with low-, intermediate-, 
and high-risk prostate cancer was more than 5 months, whereas two thirds of patients in the present study underwent RP within 3 months after diagnosis. Moreover, in the Canadian study, no information on histopathologic characteristics such as extraprostatic extension (ECE), LNI was available. As such it seems possible that the observed correlation between waiting time and risk of BCR is due to very long waiting times and inclusion of a large proportion of patients with very high-risk patients harboring non-locally confined PCa.

However, most available studies investigating this topic reported no significant influence of delayed prostatectomy on oncological outcomes $(5,7,11,12,17,23)$. For example, Morini et al. recently published a study examining the impact in patients with localized prostate cancer reporting no correlation in timefrom-biopsy-to-prostatectomy and impaired pathological results or risk of BCR (15). In another recent study by Gupta et al. these results could be confirmed. Specifically, there was no significant difference in rates of adjuvant therapy, PSM, ECE, seminal vesicle invasion, LNI or 2- and 5-year BCR-free survival between men who underwent radical prostatectomy at $<3$ months vs. 3-6 months after diagnosis (24). Also, Abern et al. observed that a waiting time of up to 9 months was not related to higher risk of BCR, ECE, PSM or histopathologic upgrading in their analyses of a large cohort of 1.561 men with low- and intermediaterisk prostate cancer undergoing radical prostatectomy (25). However, they observed an increased risk of BCR and PSM for patients with intermediate-risk prostate cancer who underwent radical prostatectomy at $>9$ months after biopsy. This observation confirms the current clinical practice to recommend definite therapy (i.e., radical prostatectomy or radiation therapy) for patients with intermediate-or high-risk prostate cancer (26).

Taken together we found no difference between prompt surgery and delayed surgery in neither the intermediate- nor the high-risk group in terms of histopathological characteristics or chance of nerve sparing in patients undergoing radical prostatectomy within 6 months.

Our results suggest that also in intermediate- and highrisk PCa patients oncological and functional outcomes after radical prostatectomy are unaffected by a delay of up to 6 months after diagnosis. Our findings might reassure patients with prostate cancer who cannot or do not want to be operated on immediately as well as their treating physicians. Our observations might be of special interest because of the ongoing discussion on treatment delay due to the current COVID-19 pandemic (27). Moreover, the focus on intermediate- and highrisk PCa patients accounts for the treatment paradigm shift in surgical PCa therapy, reflected by an inverse stage migration

\section{REFERENCES}

1. European Association of Urology. Guidelines Prostate Cancer. (2020). Available online at: https://uroweb.org/guideline/prostate-cancer/ (accessed May 10, 2020).

2. Sommers BD, Beard CJ, D’Amico AV, Dahl D, Kaplan I, Richie JP, et al. Decision analysis using individual patient preferences to determine during the last decade allowing implications for current clinical practice (18).

Due to the retrospective nature of our study several limitations apply.

First, a selection bias leading to prioritization of patients with highest risk to immediate surgical treatment might deteriorate oncologic outcomes and probability of nerve sparing surgery. This circumstance could be an explanation for the fact that in the group that was operated on within 3 months the percentage of pT3b tumors and nodal positive patients was higher than in the group that that underwent delayed surgery.

Second, we were not able to determine the specific reason for the treatment delay. In this sense we do not know whether the patient was not operated due to anxiety, medical reasons, if the surgeon refused the prostatectomy initially or if the patient seeked a second opinion.

Third, our analyzed were restricted to clinico-pathologic characteristics. As such, we don't know about (biochemical) survival or functional results.

\section{CONCLUSION}

Our data suggest that a delayed surgical treatment between 3-6 months does not affect pathological outcomes or the chance to obtain nerve sparing surgery in patients with intermediate- or high-risk prostate cancer.

\section{DATA AVAILABILITY STATEMENT}

The raw data supporting the conclusions of this article will be made available by the authors, without undue reservation.

\section{ETHICS STATEMENT}

The studies involving human participants were reviewed and approved by University Cancer Center Frankfurt: SUG-42020. The patients/participants provided their written informed consent to participate in this study.

\section{AUTHOR CONTRIBUTIONS}

TE: concept of the study and writing the publication. PM: evaluation of the statistics, results, and correction of the publication. $\mathrm{BH}$ : material and methods, and illustrations. FP, MWen, $\mathrm{CH}$, and MWel: database, and material and methods. JK and PW: evaluation pathology. MD: results. LK and FR: statistics and result. FC and AB: discussion and correction. All authors contributed to the article and approved the submitted version. localized prostate cancer-the patient or physician? Results from a population-based study. Cancer. (2013) 119:421-8. doi: 10.1002/cncr. 27738 
4. Holmes-Rovner M, Montgomery JS, Rovner DR, Scherer LD, Whitfield J, Kahn VC, et al. Informed decision making: assessment of the quality of physician communication about prostate cancer diagnosis and treatment. Med Decis Making. (2015) 35:999-1009. doi: 10.1177/0272989X15597226

5. Boorjian SA, Bianco FJ, Scardino PT, Eastham JA. Urological oncology. Does the time from biopsy to surgery affect biochemical recurrence after radical prostatectomy? BJU Int. (2005) 96:7736. doi: 10.1111/j.1464-410X.2005.05763.x

6. O'Brien D, Loeb S, Carvalhal GF, McGuire BB, Kan D, Hofer MD, et al. Delay of surgery in men with low risk prostate cancer. J Urol. (2011) 185:21437. doi: 10.1016/j.juro.2011.02.009

7. Graefen M, Walz J, Chun K-HF, Schlomm T, Haese A, Huland H. Reasonable delay of surgical treatment in men with localized prostate cancer - impact on prognosis? Eur Urol. (2005) 47:756-60. doi: 10.1016/j.eururo.2005.02.004

8. Freedland SJ, Kane CJ, Amling CL, Aronson WJ, Presti JC, Terris $\mathrm{MK}$, et al. Delay of radical prostatectomy and risk of biochemical progression in men with low risk prostate cancer. J Urol. (2006) 175:1298303. doi: 10.1016/S0022-5347(05)00646-4

9. Phillips JJ, Hall MC, Lee WR, Clark PE. Does a delay in initiating definitive therapy affect biochemical recurrence rates in men with clinically localized prostate cancer? Urol Oncol Semin Orig Invest. (2007) 25:196200. doi: 10.1016/j.urolonc.2006.06.004

10. Nam RK, Jewett MAS, Krahn MD, Robinette MA, Tsihlias J, Toi A, et al. Delay in surgical therapy for clinically localized prostate cancer and biochemical recurrence after radical prostatectomy. Can J Urol. (2003) 10:1891-8.

11. Kim SJ, Ryu JH, Yang SO, Lee JK, Jung TY, Kim YB. Does the time interval from biopsy to radical prostatectomy affect the postoperative oncologic outcomes in Korean men? J Korean Med Sci. (2019) 34:e234. doi: 10.3346/jkms.2019.34.e234

12. Khan MA, Mangold LA, Epstein JI, Boitnott JK, Walsh PC, Partin AW. Impact of surgical delay on long-term cancer control for clinically localized prostate cancer. J Urol. (2004) 172:1835-9. doi: 10.1097/01.ju.0000140277.08623.13

13. Sun M, Abdollah F, Hansen J, Trinh Q, Bianchi M, Tian Z, et al. Is a treatment delay in radical prostatectomy safe in individuals with low-risk prostate cancer? J Sexual Med. (2012) 9:2961-9. doi: 10.1111/j.1743-6109.2012.02806.x

14. Westerman ME, Sharma V, Bailey GC, Boorjian SA, Frank I, Gettman MT, et al. Impact of time from biopsy to surgery on complications, functional and oncologic outcomes following radical prostatectomy. Int Braz J Urol. (2019) 45:468-77. doi: 10.1590/s1677-5538.ibju.2018.0196

15. Morini MA, Muller RL, de Castro Junior PCB, de Souza RJ, Faria EF. Time between diagnosis and surgical treatment on pathological and clinical outcomes in prostate cancer: does it matter? World J Urol. (2018) 36:122531. doi: 10.1007/s00345-018-2251-5

16. Fossati N, Rossi MS, Cucchiara V, Gandaglia G, Dell'Oglio P, Moschini M, et al. Evaluating the effect of time from prostate cancer diagnosis to radical prostatectomy on cancer control: can surgery be postponed safely? Urol Oncol Semin Orig Invest. (2017) 35:150.e9-e15. doi: 10.1016/j.urolonc.2016. 11.010

17. Zanaty M, Alnazari M, Ajib K, Lawson K, Azizi M, Rajih E, et al. Does surgical delay for radical prostatectomy affect biochemical recurrence? A retrospective analysis from a Canadian cohort. World J Urol. (2018) 36:16. doi: 10.1007/s00345-017-2105-6

18. Leyh-Bannurah S-R, Karakiewicz PI, Pompe RS, Preisser F, Zaffuto E, Dell'Oglio $\mathrm{P}$, et al. Inverse stage migration patterns in North American patients undergoing local prostate cancer treatment: a contemporary population-based update in light of the (2012). USPSTF recommendations. World J Urol. (2019) 37:469-79. doi: 10.1007/s00345-018-2396-2

19. D'Amico AV, Whittington R, Malkowicz SB, Fondurulia J, Chen M-H, Tomaszewski JE, et al. The combination of preoperative prostate specific antigen and postoperative pathological findings to predict prostate specific antigen outcome in clinically localized prostate cancer. J Urol. (1998) 160:2096-101. doi: 10.1097/00005392-199812010-00041

20. Preisser F, Theissen L, Wild P, Bartelt K, Kluth L, Köllermann J, et al. Implementation of intraoperative frozen section during radical prostatectomy: short-term results from a German tertiary-care center. Eur Urol Focus. (2019) doi: 10.1016/j.euf.2019.03.007. [Epub ahead of print].

21. Schlomm T, Heinzer H, Steuber T, Salomon G, Engel O, Michl U, et al. Full functional-length urethral sphincter preservation during radical prostatectomy. Eur Urol. (2011) 60:320-9. doi: 10.1016/j.eururo.2011.02.040

22. Campi R, Amparore D, Capitanio U, Checcucci E, Salonia A, Fiori C, et al. Assessing the burden of nondeferrable major uro-oncologic surgery to guide prioritisation strategies during the COVID-19 pandemic: insights from three Italian high-volume referral centres. Eur Urol. (2020) 78:115. doi: 10.1016/j.eururo.2020.03.054

23. Vickers AJ, Bianco FJ, Boorjian S, Scardino PT, Eastham JA. Does a delay between diagnosis and radical prostatectomy increase the risk of disease recurrence? Cancer. (2006) 106:576-80. doi: 10.1002/cncr.21643

24. Gupta N, Bivalacqua TJ, Han M, Gorin MA, Challacombe BJ, Partin AW, et al. Evaluating the impact of length of time from diagnosis to surgery in patients with unfavourable intermediate-risk to very-high-risk clinically localised prostate cancer. BJU Int. (2019) 124:268-74. doi: 10.1111/bju.14659

25. Abern MR, Aronson WJ, Terris MK, Kane CJ, Presti JC, Amling $\mathrm{CL}$, et al. Delayed radical prostatectomy for intermediate-risk prostate cancer is associated with biochemical recurrence: possible implications for active surveillance from the SEARCH database. Prostate. (2013) 73:40917. doi: $10.1002 /$ pros. 22582

26. Mottet N, Bellmunt J, Bolla M, Briers E, Cumberbatch MG, De Santis M, et al. EAU-ESTRO-SIOG guidelines on prostate cancer. Part 1: screening, diagnosis, and local treatment with curative intent. Eur Urol. (2017) 71:61829. doi: 10.1016/j.eururo.2016.08.003

27. Stensland KD, Morgan TM, Moinzadeh A, Lee CT, Briganti A, Catto JWF, et al. Considerations in the Triage of urologic surgeries during the COVID-19 pandemic. Eur Urol. (2020) 77:663-6. doi: 10.1016/j.eururo.2020.03.027

Conflict of Interest: The authors declare that the research was conducted in the absence of any commercial or financial relationships that could be construed as a potential conflict of interest.

The handling editor declared a past co-authorship with several of the authors LK, $\mathrm{FC}$, and $\mathrm{AB}$ and the reviewer $\mathrm{KB}$ declared a past co-authorship with one of the author PM.

Copyright (c) 2020 Engl, Mandel, Hoeh, Preisser, Wenzel, Humke, Welte, Köllermann, Wild, Deuker, Kluth, Roos, Chun and Becker. This is an open-access article distributed under the terms of the Creative Commons Attribution License (CC $B Y)$. The use, distribution or reproduction in other forums is permitted, provided the original author(s) and the copyright owner(s) are credited and that the original publication in this journal is cited, in accordance with accepted academic practice. No use, distribution or reproduction is permitted which does not comply with these terms. 